\title{
The octreotide test dose is not a reliable predictor of the subsequent response to somatostatin analogue therapy in patients with acromegaly
}

Ana Pokrajac, Andrew G Claridge, S K Abdul Shakoor and Peter J Trainer

Christie Hospital NHS Trust, Department of Endocrinology, Wilmslow Road, Withington,

Manchester M2O 4BX, UK

(Correspondence should be addressed to P Trainer; Email: peter.trainer@man.ac.uk)

\begin{abstract}
In many centres, a test dose (TD) of octreotide is administered before commencing somatostatin analogue therapy (SAT), although the merits of this procedure are uncertain. We have analysed the value of the GH response to a TD in predicting the efficacy of subsequent SAT in 47 patients with acromegaly (25 male, median age 51 years, range 20-82). The primary goal of SAT was a mean GH of $<5 \mathrm{mU} / \mathrm{l}$. Median baseline $\mathrm{GH}$ was $19.3 \mathrm{mU} / \mathrm{l}(2.2-233 \mathrm{mU} / \mathrm{l})$ and with the TD fell by $78 \%$ $(35-98 \%)$ to a nadir of $4.2 \mathrm{mU} / \mathrm{l}(<0.3-85 \mathrm{mU} / \mathrm{l})$. Optimal predictive power was observed when $\mathrm{GH}$ fell to $<5 \mathrm{mU} / \mathrm{l}$ after the TD. With this criterion, the TD had a positive predictive value (PPV) of achieving the primary goal on SAT of $82 \%$ and a negative predictive value (NPV) of $50 \%$. However, baseline $\mathrm{GH}$ was also highly predictive of the likelihood of successful SAT $(\mathrm{GH}<5 \mathrm{mU} / \mathrm{l})$. The $\mathrm{GH}$ response to the TD had PPV of $83 \%$ and NPV of $61 \%$ of normalising IGF-I on SAT. In summary, baseline GH and nadir after a TD are highly predictive of a good response to SAT; however, a poor response to a TD does not exclude an optimal response to SAT. Furthermore, failure to achieve biochemical control does not equate to no benefit, as biochemical improvement was seen in every patient; therefore, no patient should be deprived of octreotide therapy because of the result of a TD. In conclusion, our data indicate that the octreotide TD has no place in selecting patients for SAT.
\end{abstract}

European Journal of Endocrinology $154267-274$

\section{Introduction}

The somatostatin analogues (SA) are the mainstay of medical therapy for acromegaly, with most patients receiving SA therapy at some point in their treatment. Octreotide is a synthetic, octapeptide SA with high affinity for the type 2 and 5 somatostatin receptors responsible for the regulation of growth hormone $(\mathrm{GH})$ secretion (1). There is a 20-year experience of the short-acting, subcutaneous preparations used in the treatment of acromegaly, administered at a dose of 100-200 $\mu \mathrm{g}$ three times daily (2). In the last decade, the short-acting formulation has been superseded by a monthly, depot preparation that offers greater convenience for patients (3). Octreotide can control GH and insulin-like growth factor (IGF-1) secretion, on average, in approximately two-thirds of patients with acromegaly and, when used as primary therapy, it can induce significant tumour shrinkage in approximately $30 \%$ of patients $(4,5)$. Lanreotide, an alternative SA of comparable potency, is available as twice-weekly or monthly preparations $(4,6,7)$.

SA are expensive and may have side effects. Thus, there has been great interest in identifying the factors which predict a good response to SA therapy (SAT), thereby focusing treatment on those most likely to respond. Studies have suggested that the response to SA is determined by tumour somatostatin receptor expression, but this is not a clinically practicable means of selecting patients for therapy (8). Pretreatment $\mathrm{GH}$ levels have been shown to predict the probability of achieving normal GH levels with long-term SAT (5). It has also been argued that the GH response to an acute dose of octreotide is of value in judging the likely response to long-term therapy. The octreotide test dose has become routine practice in many endocrine centres, but there is a dearth of data defining the criteria by which to judge the response and its predictive accuracy. The aim of this study was to analyse our experience of the octreotide test dose (TD) with the 
goal of defining optimal criteria for predicting the response to long-term octreotide therapy.

\section{Subjects and methods}

\section{Patients}

Forty-seven patients (22 female; median age 51 years, range 20-82) with acromegaly had an octreotide test between February 1988 and September 2004. Thirtyseven patients had macroadenomas; 33 patients had undergone hypophysectomy and 37 radiotherapy. There was at least a 1-year interval between radiotherapy and initiation of octreotide. Twenty patients were on a fixed dose of a dopamine agonist at the time of the octreotide test and during subsequent SAT.

\section{Protocols}

Octreotide TD Fasted patients received subcutaneously 50 or $100 \mu \mathrm{g}(n=5)$ octreotide (Sandostatin, Novartis Pharma Services, Basel, Switzerland). Blood samples were drawn through an indwelling catheter at -15 and $0 \mathrm{~min}$ and hourly for up to $9 \mathrm{~h}$. No difference was found in response between the two dose groups (42 vs 5 patients).

Assessment of disease activity The primary biochemical measure of disease activity was by calculation of the mean of five $\mathrm{GH}$ samples drawn during a single day $(\mathrm{GH}$ day curve (GHDC)) (9). In recent years, IGF-1 has been a secondary parameter in the assessment of the activity of acromegaly.

SAT After the octreotide TD, patients proceeded to SAT with either short-acting octreotide $(n=6)$, long-acting octreotide (Sandostatin LAR, Novartis; $n=35$ ) or lanreotide (Somatuline Autogel, Ipsen Ltd, Slough, Berks, UK; $n=1$ ). The dose of SAT was titrated with the primary goal of achieving a mean $\mathrm{GH}$ of $<5 \mathrm{mU} / \mathrm{l}$ during a GHDC. A secondary goal was to lower IGF-I into the reference range.

\section{Assays}

GH Until 2000, GH was measured by immunoradiometric assay (Netria, London, UK) (sensitivity $0.5 \mathrm{mU} / \mathrm{l}$; inter- and intra-assay coefficients of variation (CV) of $<5 \%$ ); now one uses a two-site chemiluminiscence immunoassay (Nichols Advantage; Nichols Institute Diagnostics, San Clemente, CA, USA) (sensitivity $0.3 \mathrm{mU} / \mathrm{l}$, intra-assay $\mathrm{CV} 4.2-8.0 \%$, interassay $\mathrm{CV}$ $4.1-12.1 \%)$.

IGF-I Until 2000, IGF-I was measured by in-house RIA with a single reference range for adults $(8-38 \mathrm{nmol} / \mathrm{l}$, precision and reproducibility of $<10 \%$ ). This was replaced with a two-site chemiluminescence immunoassay (Nichols Advantage), with the age-related reference range provided by the manufacturer. Since 2003, age- and gender-related reference ranges have been used (10). The precision of this assay is $4.4-5.2 \%$ with reproducibility of $5.7-7.4 \%$ and limit of sensitivity of $6 \mu \mathrm{g} / \mathrm{l}$.

\section{Statistical analysis}

The data had a skewed distribution; therefore, non-parametric tests were used. Correlation analysis was performed by Spearman's rank correlation test. Sensitivity, specificity, and positive and negative predictive value (PPV and NPV) were calculated as follows: sensitivity $=$ true positives/(true positives + false negatives); specificity $=$ true negatives/(true negatives + false positives); PPV $=$ true positives/(true positives + false positives); NPV $=$ true negatives/(true negatives + false negatives). Numerous criteria were examined to establish the optimal PPV and NPV of the TD, and it was concluded that the criteria providing the best prediction of the subsequent response to SAT were a mean $\mathrm{GH}$ of $<5 \mathrm{mU} / \mathrm{l}$ and a percentage fall of $>50 \%$ and $>75 \%$ in $\mathrm{GH}$ values during the TD.

\section{Results}

No data on SAT are available in five patients (three failed to attend for follow-up, one entered a clinical study and one discontinued therapy due to severe gastrointestinal side effects). In the remaining 42, the median duration of follow-up was 2 years (range 3 months to 13 years), and the median doses were $30 \mathrm{mg}$ per month $(10-60 \mathrm{mg}), 300 \mu \mathrm{g}$ per day $(150-600 \mu \mathrm{g})$ and $40 \mathrm{mg}$ per month for long-acting octreotide $(n=35)$, octreotide $(n=6)$ and lanreotide $(n=1)$ respectively.

\section{Response to SAT}

Individual values for pretreatment $\mathrm{GH}$ levels, nadir $\mathrm{GH}$ after TD and during SAT are illustrated in Fig. 1. The mean pretreatment $\mathrm{GH}$ during a GHDC was $19.3 \mathrm{mU} / \mathrm{l}$ (range 2.2-233 mU/l). The lowest mean GH achieved on SAT was $3.6 \mathrm{mU} / \mathrm{l}$ (range $<0.3-26.6 \mathrm{mU} / \mathrm{l}$ ), while median percentage fall during SAT was $83 \%$ (range $-35 \%$ to $+98 \%)$. Sixty-four per cent of patients achieved a mean GH during GHDC of $<5 \mathrm{mU} /$.

\section{Response to octreotide TD}

There was a positive correlation between pretreatment and nadir GH values during the TD $(r=0.741$, $P<0.001)$. The median $\mathrm{GH}$ value fell from a baseline of $19.3 \mathrm{mU} / \mathrm{l}$ (range $2.2-233 \mathrm{mU} / \mathrm{l}$ ) to a nadir of $4.3 \mathrm{mU} / \mathrm{l}$ (range $<0.3-85 \mathrm{mU} / \mathrm{l}$ ), the nadir occurring 


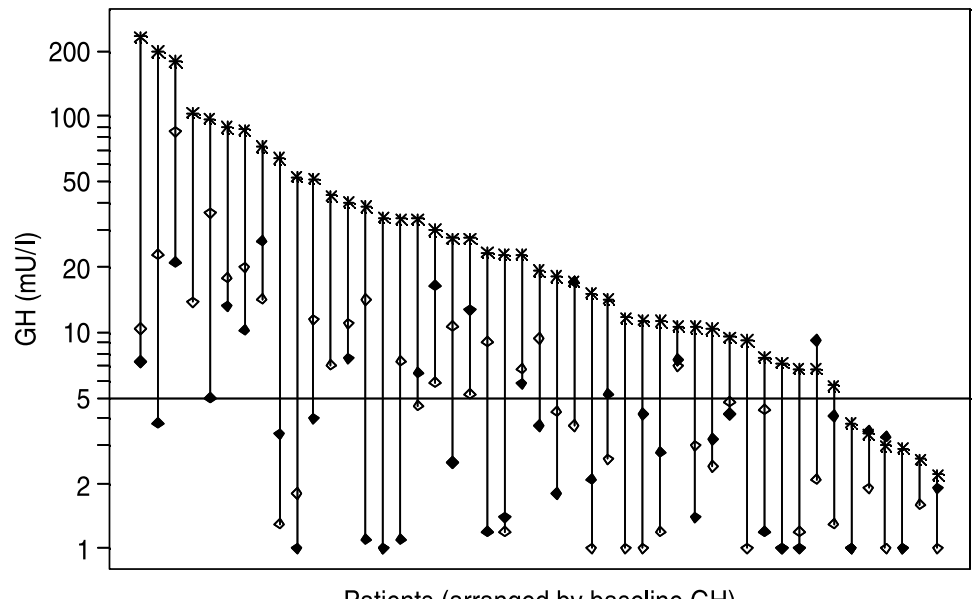

Figure 1 The pretreatment $\mathrm{GH}$ value (*), the nadir following the test dose $(\diamond)$ and the lowest result on SAT therapy $(\diamond)$ are plotted for individual patients. The target of therapy was a mean GH during a GHDC of $<5 \mathrm{mU} / \mathrm{l}(-)$. GH values are given on a log scale. at a median interval of $180 \mathrm{~min}$ (range 60-540 min). The median fall in $\mathrm{GH}$ was $78 \%$ (range 35-98\%). Fifty-seven per cent of patients achieved a nadir $\mathrm{GH}$ of $<5 \mathrm{mU} / \mathrm{l}$ (Fig. 1). As described above, octreotide TD was analysed to optimise prediction of the subsequent response to SAT. One absolute criterion and two relative evaluating criteria were established as follows:

- mean GH nadir of $<5 \mathrm{mU} / \mathrm{l}$ during a GHDC

- over 50\% decline in GH between the TD baseline and nadir

- over $75 \%$ decline in $\mathrm{GH}$ between the TD baseline and nadir.

\section{Relationship between the TD and the response to SAT}

There was a positive correlation between the GH nadir after TD and the best mean GH on SAT $(r=0.54$,
$P<0.001$ ) (Fig. 2). The highest PPV (82\%) of achieving the desired GH on SAT of $<5 \mathrm{mU} / \mathrm{l}$ was observed for TD nadir of $<5 \mathrm{mU} / \mathrm{l}$. Percentage falls of $>50 \%$ and $>75 \%$ in $\mathrm{GH}$ values after TD had PPVs of the subsequent response to SAT of $69 \%$ and $72 \%$ respectively. Nevertheless, the NPVs of all criteria were unsatisfactory, standing at 50\%, 38\% and 40\% respectively (Tables 1 and 2 and Figs 2-3), indicating that patients who did not have the desired response to a TD might still respond to SAT.

\section{Relationship between pretreatment GH values and the response to SAT}

There was a positive correlation between pretreatment $\mathrm{GH}$ values and those during SAT $(r=0.38, \quad P=$ 0.001) (Fig. 4). The pretreatment GH values were highly predictive of the response to SAT. Eighty-one per cent of patients with a mean pretreatment GH during a GHDC of $<20 \mathrm{mU} / \mathrm{l}$ obtained the desired mean $\mathrm{GH}$

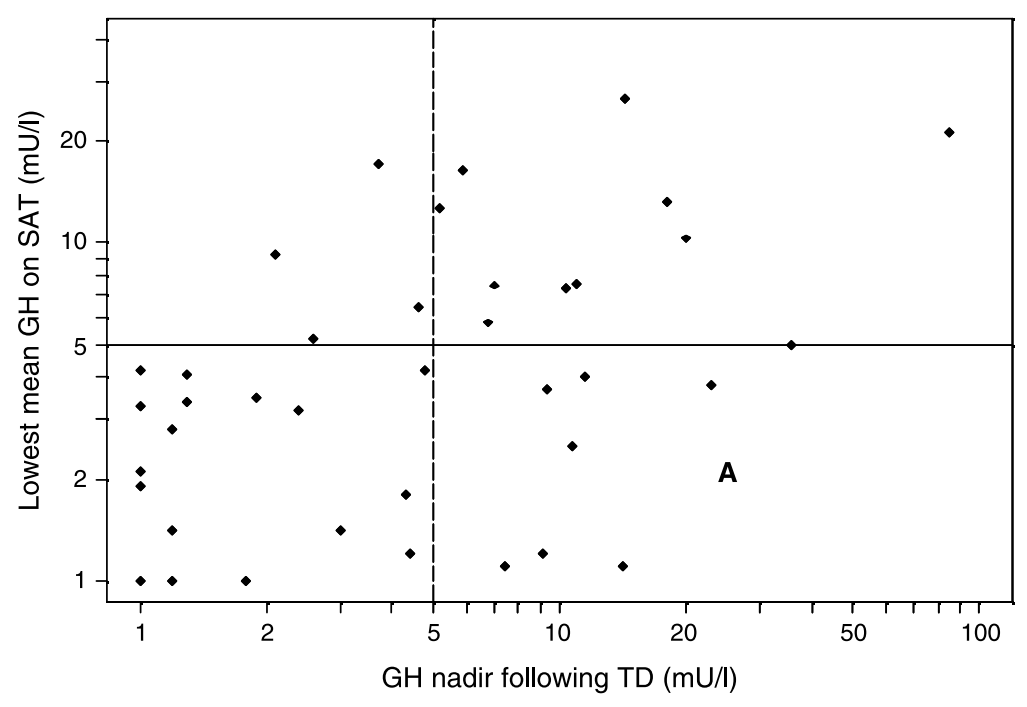

Figure 2 A positive correlation $(r=0.54$, $P<0.001)$ is seen between the GH nadir following a TD and the lowest mean GH obtained on SAT. The goal of therapy was a mean $\mathrm{GH}$ of $<5 \mathrm{mU} / \mathrm{l}$, and the optimal predictive performance of the TD was obtained with a GH nadir of $<5 \mathrm{mU} / \mathrm{l}$. Patients in quadrant $A$ did not achieve a GH nadir following the TD of $<5 \mathrm{mU} / \mathrm{l}$ but subsequently did during SAT. GH values are given on log scales. 
Table 1 The probability of achievement of disease control with somatostatin analogue therapy (SAT) is predicted by the pretreatment GH levels.

\begin{tabular}{lrrr}
\hline Baseline GH $(\mathrm{mU} / \mathrm{l})$ & $\boldsymbol{n}$ & Achieved GH nadir $<\mathbf{5}$ $\mathbf{m U / l}$ following TD & Achieved GH nadir $<\mathbf{5}$ mU/l on SAT \\
\hline$<20$ & 21 & $19 / 21(90 \%)$ & $17 / 21(81 \%)$ \\
$20-60$ & 13 & $4 / 13(31 \%)$ & $8 / 13(62 \%)$ \\
$>60$ & 8 & $1 / 8(13 \%)$ & $2 / 8(25 \%)$ \\
All & 42 & $24 / 42(57 \%)$ & $27 / 42(64 \%)$ \\
\hline
\end{tabular}

of $<5 \mathrm{mU} / \mathrm{l}$ during SAT, the results for patients with mean pretreatment $\mathrm{GH}$ of $20-60 \mathrm{mU} / \mathrm{l}$ and $>60 \mathrm{mU} / \mathrm{l}$ being $62 \%$ and $25 \%$ respectively (Fig. 4 ).

\section{Relationship between the TD and IGF-I response to SAT}

At study entry, 22/32 patients in whom a baseline IGFI was available had an IGF-I value above the upper limit of the reference range (ULRR). The primary reason to treat in the remaining patients was elevated GH levels.

In the 22 patients with an initially elevated IGF-I, SAT resulted in a fall of IGF-I from a median of $107 \%$ above ULRR (range $29-290 \%$ ) to $1 \%$ above ULRR $(-87 \%$ to $+146 \%)$, with normalisation being seen in 11 patients (50\%). Median pretreatment IGF-I value expressed relative to the ULRR was higher in the patients in whom IGF-I did not normalise on treatment $(140 \%$ (range $61-$ $290 \%$ ) vs $29 \%$ (range $-71 \%$ to $+242 \%$ ); $P<0.001$ ). The best predictor of normalisation of IGF-I (PPV 83\%, NPV $61 \%$ ) was a $\mathrm{GH}$ nadir of $<5 \mathrm{mU} / \mathrm{l}$ after the TD. Although there was a positive correlation $(r=0.48$, $P=0.002$ ) between GH and IGF-I during long-term SAT, results were discrepant in $27 \%$ of patients, with elevated IGF-I and mean GH of $<5 \mathrm{mU} / \mathrm{l}$ in $12 \%$, and normal IGF-I and elevated GH in 15\%.

\section{Discussion}

In many centres, the assessment of the $\mathrm{GH}$ response to a TD of octreotide has been routine clinical practice since the introduction of octreotide therapy almost 20 years ago and has even been used as an entry criterion for octreotide therapy studies $(11-13)$. The rationale for performing the test and the interpretation of the results have been largely undefined. Although it has been argued that the response to a TD of octreotide predicts the response to subsequent SAT, there is a lack of accepted guidelines for judging the response (14-16). To date, there have been five detailed analyses of the merits of the TD reported which reached markedly differing conclusions (Table 3) (17-21).

Colao et al. (17) reported the $\mathrm{GH}$ response to $100 \mu \mathrm{g}$ s.c. octreotide in 68 patients. The response was judged by calculating the mean of $\mathrm{GH}$ samples collected at $2-6 \mathrm{~h}$ after octreotide, rather than the nadir $\mathrm{GH}$ value reported here. Pretreatment GH values correlated with the best mean $\mathrm{GH}$ on treatment, although only $41 \%$ achieved the desired $\mathrm{GH}$ levels of $<5 \mu \mathrm{g} / \mathrm{l}$. The authors defined a positive response to the TD as a decrease in $\mathrm{GH}$ of $>50 \%$, and by this definition, the TD had a PPV of $43 \%$ and NPV of $78 \%$ of achieving normalisation of GH during long-term octreotide treatment. Colao et al. (17) concluded that the TD was not a suitable means of identifying patients who would respond to long-term octreotide therapy.

Recently, Karavitaki et al. (18) reported the relationship between the TD and SAT in 30 patients. With $100 \mu \mathrm{g}$ octreotide, $75 \%$ of patients achieved the desired $\mathrm{GH}$ levels of $<5 \mathrm{mU} / \mathrm{l}$. With receiver operating characteristics (ROC) curves to optimise the diagnostic value of the TD, $100 \%$ sensitivity and $80 \%$ specificity could be achieved (using the criterion of a $\mathrm{GH}$ nadir of $<5.25 \mathrm{mU} / \mathrm{l}$ ), which equates to a PPV of $94 \%$ and NPV of $100 \%$. For lanreotide, the best results were obtained with the criterion of $\mathrm{GH}$ nadir of $<6.05 \mathrm{mU} / \mathrm{l}$ (sensitivity 92\%, specificity 67\%, PPV $92 \%$, NPV 67\%). However, it must be appreciated that $\mathrm{GH}$ assays lack the performance to allow such precise measurement, and thus diagnostic accuracy inevitably deteriorates when more practicable criteria are applied. Karavitaki et al. (18) concluded that the TD is a reliable tool for the selection of patients with active acromegaly that will achieve 'safe' GH levels on therapy with octreotide LAR.

Table 2 The positive and negative predictive value (PPV, NPV), sensitivity and specificity of achieving target GH of $<5 \mathrm{mU} / \mathrm{l}$ on SAT for different TD criteria.

\begin{tabular}{lccc}
\hline Mean GH on SAT $<\mathbf{5} \mathbf{~ m U / l}$ & GH nadir following TD $<\mathbf{5} \mathbf{~ m U / l}$ & GH fall $>\mathbf{5 0} \%$ following TD & GH fall $>\mathbf{7 5} \%$ following TD \\
\hline PPV (\%) & 82 & 69 & 72 \\
NPV (\%) & 50 & 38 & 40 \\
Sensitivity (\%) & 67 & 81 & 67 \\
Specificity (\%) & 69 & 23 & 46 \\
\hline
\end{tabular}




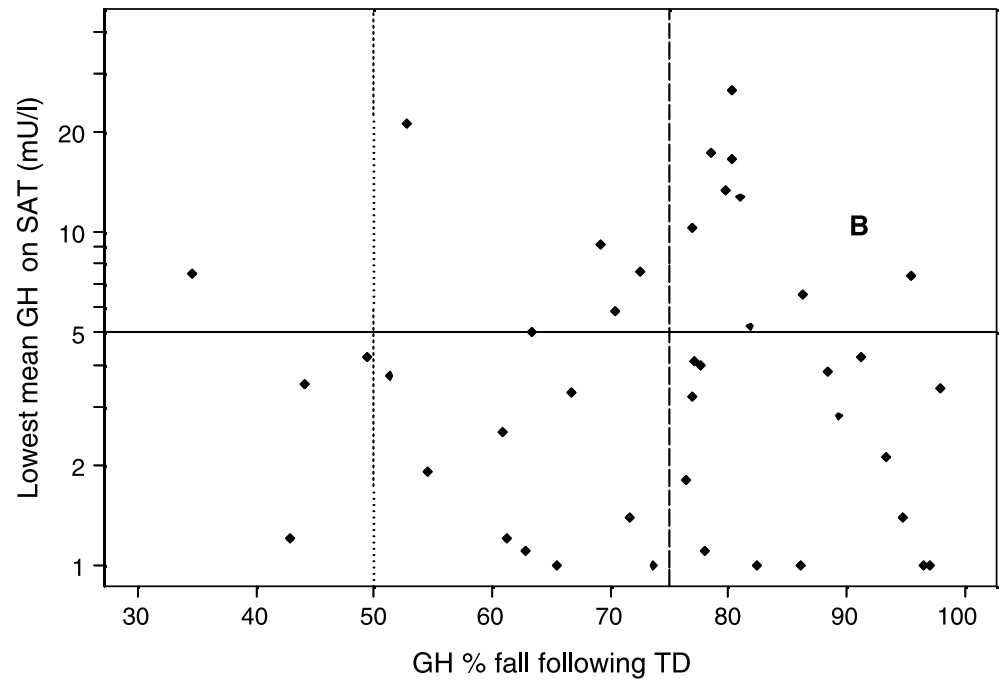

Figure 3 No significant correlation $(r=-0.06$, $P=0.72$ ) is seen between the percentage fall in GH after the TD and mean GH on SAT. Despite falls in $\mathrm{GH}$ values following the TD of $>75 \%$, patients in quadrant $\mathrm{B}$ failed to normalise $\mathrm{GH}$ during treatment.
Biermasz et al. (19) analysed the relationship between the response to the acute test $(50 \mu \mathrm{g}$ i.v. octreotide) and the outcome of 'chronic octreotide LAR treatment' in 18 patients with acromegaly. A nadir $\mathrm{GH}$ of $<5 \mathrm{mU} / \mathrm{l}$ during the TD predicted with $100 \%$ sensitivity and specificity $\mathrm{GH}$ levels of $<5 \mathrm{mU} / \mathrm{l}$ on treatment. However, GH and IGF-I results were discrepant in 33\% of patients, and the $\mathrm{GH}$ response to the TD was a poor predictor of normalisation of IGF-I (PPV 73\%, NPV 57\%). Despite this, the authors supported the use of the acute test as a predictor of the response to octreotide treatment.

Gilbert et al. (20) reviewed the results of a TD (50 $\mu \mathrm{g}$ sc octreotide) in 33 patients. A TD GH nadir of $<5 \mathrm{mU} / \mathrm{l}$ had $80 \%$ sensitivity and $83 \%$ specificity in predicting a mean $\mathrm{GH}<5 \mathrm{mU} / \mathrm{l}$ (defined goal of therapy) during SAT, from which the authors judged the TD useful. However, a fifth of patients who achieved $\mathrm{GH}<5 \mathrm{mU} / \mathrm{l}$ on treatment had a $\mathrm{GH}$ nadir $>5 \mathrm{mU} / \mathrm{l}$ following TD and on that basis would not have qualified for SAT. Furthermore, the majority (10/14) of patients classified by their GH levels as in remission had IGF-I above upper limit of reference range.

De Herder et al. (21) applied 2 relative $(>50$ or $75 \%$ fall) and 2 absolute criteria (nadir $\mathrm{GH}<1.1$ or $2 \mathrm{mcg} / \mathrm{l}$ ), all arbitrary, in their analysis of the TD performance in 24 therapy-naïve patients. In contrast to the other groups, the primary goal of therapy was to normalise IGF-I, with a $>50 \%$ fall in GH during the TD having sensitivity and negative predictive value of $100 \%$. No patient in whom GH failed to fall by $>50 \%$ during the TD did normalise IGF-I on the treatment; however, the other criteria were of little value and the authors concluded that the acute test was unnecessary prior to Sandostatin LAR therapy.

In contrast to Colao et al. (17) and De Herder et al. (21), our study and the other recent ones (18-20) had as the primary goal of therapy a mean $\mathrm{GH}$

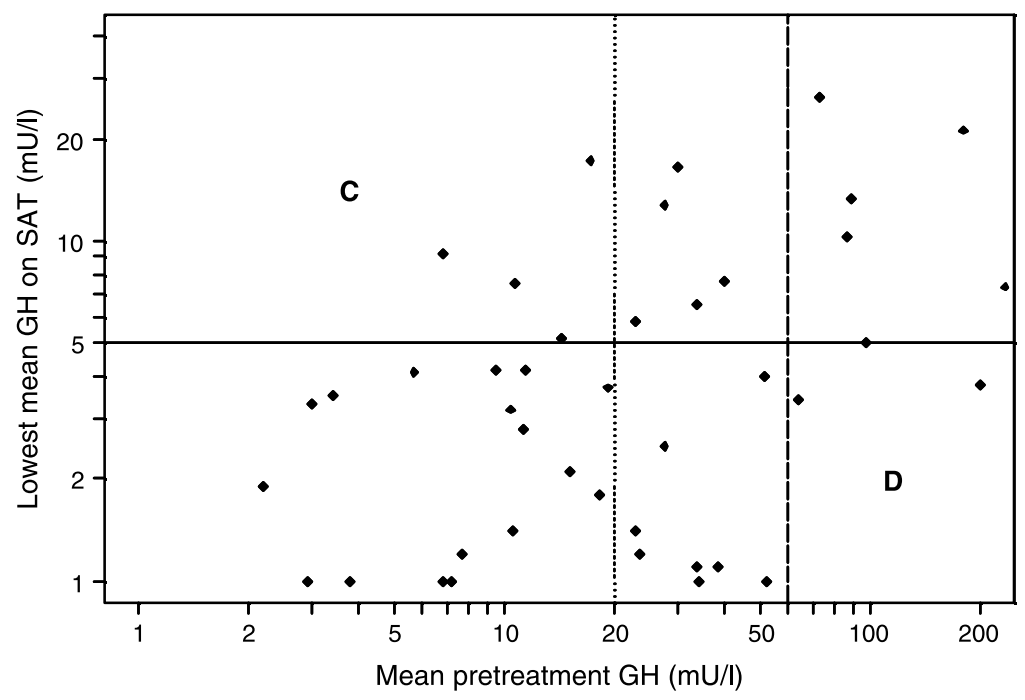

Figure 4 The pretreatment $\mathrm{GH}$ value is predictive $(r=0.38, P=0.001)$ of the lowest $\mathrm{GH}$ value during SAT. However, as can be seen in quadrant $\mathrm{C}$, patients with barely elevated $\mathrm{GH}$ values can fail to achieve $\mathrm{GH}$ values during SAT of $<5 \mathrm{mU} / \mathrm{l}$, the opposite being seen in quadrant $\mathrm{D}$. 
Table 3 A review of publications assessing the usefulness of the octreotide TD.

\begin{tabular}{|c|c|c|c|c|c|c|}
\hline Publication & Test dose $P$ & Patient nos & TD criteria & Treatment goal & Predictive value of TD & Conclusion \\
\hline Colao et al. 1996 (17) & $100 \mu \mathrm{g}$ s.c. & 68 & Mean $\mathrm{GH} 50 \%$ fall & $\mathrm{GH}<5 \mu \mathrm{g}$ & $\begin{array}{l}\text { PPV } 43 \% \\
\text { NPV } 78 \%\end{array}$ & Not valuable \\
\hline Karavitaki et al. 2005 (18) & $100 \mu \mathrm{g}$ s.c. & 30 & Nadir GH $<5.25 \mathrm{mU} / \mathrm{l}$ & $\begin{array}{l}\mathrm{GH}<5 \mathrm{mU} / \mathrm{l} \text { octreotide } \\
<6.05 \mathrm{mU} / \mathrm{l} \text { lanreotide }\end{array}$ & $\begin{array}{l}\text { sens. } 100 \% \\
\text { spec. } 80 \% \\
\text { PPV } 94 \% \\
\text { NPV } 100 \% \\
\text { sens. } 92 \% \\
\text { spec. } 67 \% \\
\text { PPV } 92 \% \\
\text { NPV } 67 \%\end{array}$ & Reliable selection tool for octreotide \\
\hline Biermasz et al. 2005 (19) & $50 \mu \mathrm{g}$ i.v. & 18 & Nadir GH $<5 \mathrm{mU} / \mathrm{l}$ & $\begin{array}{l}\mathrm{GH}<5 \mathrm{mU} / \mathrm{l} \\
\text { Norm. IGF-1 }\end{array}$ & $\begin{array}{l}\text { sens. } 100 \% \\
\text { spec. } 100 \% \\
\text { PPV } 73 \% \\
\text { NPV } 57 \%\end{array}$ & Useful \\
\hline Gilbert et al. 2005 (20) & $50 \mu \mathrm{g}$ s.c. & 33 & Nadir $\mathrm{GH}<5 \mathrm{mU} / \mathrm{l}$ & $\mathrm{GH}<5 \mathrm{mU} / \mathrm{l}$ & $\begin{array}{l}\text { sens. } 80 \% \\
\text { spec. } 83 \%\end{array}$ & Useful \\
\hline De Herder et al. 2005 (21) & $50 \mu \mathrm{g}$ s.c. & 28 & $\begin{array}{l}>75 \% \text { fall } \\
\text { Nadir GH }<1.1 \mu \mathrm{g} \\
<2 \mu \mathrm{g}\end{array}$ & $\begin{array}{l}\text { Norm. IGF-1 } \\
\text { Norm. IGF-1 }\end{array}$ & $\begin{array}{l}\text { sens. } 100 \% \\
\text { spec. 38\% } \\
\text { PPV } 58 \% \\
\text { NPV } 100 \% \\
\text { sens. } 73 \% \\
\text { spec. } 77 \% \\
\text { PPV } 73 \% \\
\text { NPV } 77 \% \\
\text { sens. 55\% } \\
\text { spec. } 85 \% \\
\text { PPV } 75 \% \\
\text { NPV } 69 \% \\
\text { sens. } 82 \% \\
\text { spec. } 46 \% \\
\text { PPV } 56 \% \\
\text { NPV } 75 \%\end{array}$ & Not recommended \\
\hline Pokrajac et al. 2005 (Present study) & $50 / 100 \mu \mathrm{g}$ s.c. & 47 & $\mathrm{GH}>75 \%$ fall & $\begin{array}{l}\mathrm{GH}<5 \mathrm{mU} / \mathrm{l} \\
\text { Norm. IGF-1 } \\
\mathrm{GH}<5 \mathrm{mU} / \mathrm{l} \\
\text { Norm. IGF-1 }\end{array}$ & $\begin{array}{l}\text { sens. } 67 \% \\
\text { spec. } 69 \% \\
\text { PPV } 82 \% \\
\text { NPV } 50 \% \\
\text { sens. } 74 \% \\
\text { spec. } 73 \% \\
\text { PPV } 83 \% \\
\text { NPV } 61 \% \\
\text { sens. } 67 \% \\
\text { spec. } 46 \% \\
\text { PPV } 72 \% \\
\text { NPV } 40 \% \\
\text { sens. } 67 \% \\
\text { spec. } 53 \% \\
\text { PPV } 72 \% \\
\text { NPV } 47 \%\end{array}$ & $\begin{array}{l}\text { No place in the assessment should } \\
\text { be abandoned }\end{array}$ \\
\hline
\end{tabular}


of $<5 \mathrm{mU} / \mathrm{l}(22,23)$, and nadir rather than mean values following the octreotide TD were analysed. The difference in therapeutic goal between the studies is irrelevant to the analysis of the TD as in all studies the dose of SAT was titrated to achieve the predetermined therapeutic goal.

In our study, the best predictive value of the TD (PPV $82 \%$, NPV $50 \%$ ) was achieved using the criterion of a $\mathrm{GH}$ nadir $<5 \mathrm{mU} / \mathrm{l}$ during TD, with patients meeting this criterion consistently achieving the desired goal during long-term treatment of mean $\mathrm{GH}$ during GHDC of $<5 \mathrm{mU} / \mathrm{l}$. While a positive response to a TD predicts a good response to subsequent therapy, the limitation of the test is that failure to respond to a TD does not preclude achieving GH values of $<5 \mathrm{mU} / \mathrm{l}$ on long-term treatment. Twenty-seven percent of patients who did not respond to a TD went on to achieve GH levels of $<5 \mathrm{mU} / \mathrm{l}$ during SAT; therefore, no patient should be denied SAT based on a failure to respond to a TD.

The case for performing octreotide tests is further undermined by our confirmation of the previously reported correlation between pre-treatment $\mathrm{GH}$ values and the best mean GH values achieved on subsequent SAT (5). In our study pretreatment GH values were highly predictive of the probability of achieving a $\mathrm{GH}$ of $<5 \mathrm{mU} / \mathrm{l}$ with treatment. Eighty-one percent of patients with a pretreatment $\mathrm{GH}<20 \mathrm{mU} / \mathrm{l}$ achieved the desired GH levels, which contrasts with only $25 \%$ of patients with pretreatment $\mathrm{GH}$ levels $>60 \mathrm{mU} / \mathrm{l}$. Furthermore, failure to achieve the desired $\mathrm{GH}$ of $<5 \mathrm{mU} / \mathrm{l}$ does not mean that patients have not benefited from octreotide therapy; in our cohort of such patients mean $\mathrm{GH}$ levels fell by a median of $78 \%$ (range $-35 \%$ to $100 \%$ ) and IGF-I reduced from $140 \%$ ULRR (range $61-290 \%$ ) to $41 \%$ ULRR (range $5-146 \%)$.

Our study and those of De Herder et al. (21) and Biermasz et al. (19) are the first to report the value of the octreotide TD in predicting the IGF-I response to SAT. As with GH, we found that the higher the baseline IGF-I, the less the likelihood of normalisation with treatment. The absence of a response to a TD of octreotide does not preclude normalisation of IGF-I during long-term SAT. IGF-I is increasingly being used as the primary goal of therapy in patients with acromegaly in which case the use of the GH response to a TD of octreotide is of even more limited value. In our study, IGF-I remained elevated in $12 \%$ of patients obtaining a mean $\mathrm{GH}$ of $<5 \mathrm{mU} / \mathrm{l}$.

In conclusion, our data indicate that the octreotide TD is able to predict a positive response to SAT therapy. However, the limitation of the test is that failure to respond to a TD does not preclude a good response to long-term therapy. Therefore, it would be inappropriate to deprive a patient of octreotide treatment because of a poor response to a test dose. Furthermore, even if a patient fails to achieve an optimal response to treatment, defined 
here as a mean $\mathrm{GH}<5 \mathrm{mU} / \mathrm{l}$, there is still symptomatic and long-term benefit from lowering GH and IGF-I levels, in this study by $78 \%$ and $44 \%$ respectively. The octreotide TD has no place in the assessment of patients prior to octreotide therapy and should be abandoned.

\section{References}

1 Plewe G, Beyer J, Krause U, Neufeld M \& Del Pozo E. Long-acting and selective suppression of growth hormone secretion by somatostatin analogue SMS 201-995 in acromegaly. Lancet 19842 (8406) 782-784.

2 Lamberts SWJ, Van der Lely AJ, Herder WW \& Hofland LJ. Octreotide. New England Journal of Medicine 1996334 246-254.

3 Stewart PM, Kane KF, Stewart SE, Lancranjan I \& Sheppard MC. Depot long-acting somatostatin analog (Sandostatin-LAR) is an effective treatment for acromegaly. Journal of Clinical Endocrinology and Metabolism $1995803267-3272$.

4 Freda PU. Somatostatin analogues in acromegaly. Journal of Clinical Endocrinology and Metabolism 200287 3013-3018.

5 Bevan JS, Atkin SL, Atkinson AB, Bouloux PM, Hanna F, Harris PE, James RA, McConnell M, Roberts GA, Scanlon MF, Stewart PM, Teasdale E, Turner HE, Wass JAH \& Wardlaw JM. Primary medical therapy for acromegaly: an open, prospective, multicenter study of the effects of subcutaneous and intramuscular slow-release octreotide on growth hormone, insulin-like growth factor-I, and tumor size. Journal of Clinical Endocrinology and Metabolism 200287 4554-4563.

6 Heron I, Thomas F, Dero M, Gancel A, Ruiz JM, Schatz B \& Kuhn JM. Pharmacokinetics and efficacy of a long-acting formulation of the new somatostatin analog BIM 23014 in patients with acromegaly. Journal of Clinical Endocrinology and Metabolism $199376721-727$

7 Attanasio R, Baldelli R, Pivonello R, Grottoli S, Bocca L, Gasco V, Giusti M, Tamburrano G, Colao A \& Cozzi R. Lanreotide $60 \mathrm{mg}$, a new long-acting formulation: effectiveness in the chronic treatment of acromegaly. Journal of Clinical Endocrinology and Metabolism $2003 \mathbf{8 8} 5258-5265$.

8 Reubi JC \& Landolt AM. The growth hormone responses to octreotide in acromegaly correlate with adenoma somatostatin receptor status. Journal of Clinical Endocrinology and Metabolism 198968 $844-850$

9 Kaltsas GA, Isidori AM, Florakis D, Trainer PJ, CamachoHubner C, Afshar C, Sabin I, Jenkins JP, Chew SL, Monson JP, Besser GM \& Grossman AB. Predictors of the outcome of surgical treatment in acromegaly and the value of the mean growth hormone day curve in assessing postoperative disease activity. Journal of Clinical Endocrinology and Metabolism 200186 1645-1652.

10 Brabant G, Von zur Muhlen A, Wuster C, Ranke MB, Kratzsch J, Kiess W, Ketelslegers JM, Wilhelmsen L, Hulthen L, Saller B, Mattsson A, Wilde J, Schemer R, Kann P \& German KIMS Board. Serum insulin-like growth factor I reference values for an automated chemiluminescence immunoassay system: results from a multicenter study. Hormone Research 200360 53-60.
11 Flogstad AK, Halse J, Bakke S, Lancranjan I, Marbach P, Bruns CH \& Jervell J. Sandostatin LAR in acromegalic patients: long term treatment. Journal of Clinical Endocrinology and Metabolism 1997 $8223-28$.

12 Lancranjan I \& Atkinson AB. Results of a European multicentre study with Sandostatin LAR in acromegalic patients. Sandostatin LAR Group. Pituitary 19991 105-114.

13 Ezzat S, Redelmeier DA, Gnhelm M \& Harris AG. A prospective multicenter octreotide dose response study in the treatment of acromegaly. Journal of Endocrinological Investigation $1999 \mathbf{1 8}$ $364-369$.

14 Pieters GFFM, Smals AGH \& Kloppenborg PWC. Long-term treatment of acromegaly with the somatostatin analogue SMS 201995 [Letter]. New England Journal of Medicine 19863141391.

15 Lamberts SW, Uitterlinden P \& Del Pozo E. SMS 201-995 induces a continuous decline in circulating growth hormone and somatomedin-C levels during therapy of acromegalic patients for over two years. Journal of Clinical Endocrinology and Metabolism $198765703-710$.

16 Lamberts SW, Uitterlinden P, Schuijff PC \& Klijn JG. Therapy of acromegaly with sandostatin: the predictive value of an acute test, the value of serum somatomedin-C measurements in dose adjustment and the definition of a biochemical 'cure'. Clinical Endocrinology (Oxford) 198829 411-420.

17 Colao A, Ferone D, Lastoria S, Marzullo P, Cerbone G, Di Sarno A, Longobardi S, Merola B, Salvatore M \& Lombardi G. Prediction of efficacy of octreotide therapy in patients with acromegaly. Journal of Clinical Endocrinology and Metabolism $1996812356-2362$.

18 Karavitaki N, Botusan I, Radian S, Coculescu M, Turner HE \& Wass JAH. The value of an acute octreotide suppression test in predicting long-term responses to depot somatostatin analogues in patients with active acromegaly. Clinical Endocrinology (Oxford) 200562 282-288.

19 Biermasz NR, Pereira AM, Smit JW, Romijn JA \& Roelfsema F. Intravenous octreotide test predicts the long term outcome of treatment with octreotide-long-acting repeatable in active acromegaly. Growth Hormone and IGF Research 200515 200-206.

20 Gilbert JA, Miell JP. Chambers SM, McGregor AM \& Aylwin SJ. The nadir growth hormone after an octreotide test dose predicts the long-term efficacy of somatostatin analogue therapy in acromegaly. Clinical Endocrinology (Oxford) 200562 742-747.

21 De Herder WW, Taal HR, Uitterlinden P, Feelderrs RA, Janssen J \& van der Lely AJ. Limited predictive value of an acute test with subcutaneous octreotide for long-term IGF-I normalization with Sandostatin LAR in acromegaly. European Journal of Endocrinology $200515367-71$.

22 Bates AS, Van't Hoff W, Jones JM \& Clayton PE. An audit of outcome of treatment in acromegaly. Quarterly Journal of Medicine $199386293-299$.

23 Orme SM, McNally RJ \& Cartwright PE. Mortality and cancer incidence in acromegaly: a retrospective cohort study. United Kingdom Acromegaly Study Group. Journal of Clinical Endocrinology and Metabolism $1998 \mathbf{8 3} 2730-2734$.

Received 31 August 2005

Accepted 17 October 2005 